\title{
Effective Moment of Inertia Prediction of FRP-Reinforced Concrete Beams Based on Experimental Results
}

\author{
S. Roohollah Mousavi ${ }^{1}$ and M. Reza Esfahani ${ }^{2}$
}

\begin{abstract}
Concrete beams reinforced with glass-fiber reinforced polymer (GFRP) bars exhibit large deflections in comparison with steel-reinforced concrete beams because of the low modulus of elasticity of GFRP bars. This paper proposes new equations for estimating the effective moment of inertia of FRP-reinforced concrete beams on the basis of the genetic algorithm and experimental results. Genetic algorithm is used to optimize the error function between experimental and analytical responses. In the experimental part of the study, nine beam specimens were manufactured and tested. In addition, the results of 55 beam specimens tested by other researchers were also used. The effects of elastic modulus of FRP bars, reinforcement ratio, and the level of loading on the effective moment of inertia are taken into account. The proposed equations are compared with different code provisions and previous models for predicting the deflection of FRP-reinforced concrete beams. The values calculated using the proposed equations are also compared with different test results. The experimental results correlated well with the values predicted using the proposed equations, especially in the cases of high reinforcement ratios and high levels of loading. DOI: 10.1061/(ASCE)CC.1943-5614.0000284. (ㅇ 2012 American Society of Civil Engineers.
\end{abstract}

CE Database subject headings: Deflection; Fiber reinforced polymer; Algorithms; Concrete beams; Experimentation.

Author keywords: Deflection; Effective moment of inertia; FRP bars; Genetic algorithm; Reinforced concrete beams; Tension stiffening.

\section{Introduction}

Steel reinforcing bars have not performed well in applications where members were subjected to corrosive environments. Several techniques have been used to reduce the risk of reinforcement corrosion, such as using epoxy-coated reinforcing bars, decreasing the permeability of the concrete, increasing the concrete cover, waterproofing the concrete, and cathodic protection. However, none of these methods have proven effective as long-term solutions. Fiber reinforced polymer (FRP) bars can be effectively used as a reinforcing material in corrosive environments because of their corrosion-resistant property. Initial investment for constructing structures exposed to corrosion, difficulties in retrofitting damaged members, and the price of maintenance are some of the economic reasons for using fiber reinforced polymer (FRP) bars.

Fiber reinforced polymer bars have different types of fibers including glass (GFRP), carbon (CFRP), and aramid (AFRP), and are available in different grades of tensile strength and modulus of elasticity. Among the different types of current FRP composites for infrastructure applications, CFRP bars are generally the least prone to fatigue failure. The modulus of elasticity and tensile strength of CFRP bars are greater than those of AFRP and GFRP bars. GFRP reinforcing bars have a lower modulus of elasticity and tensile

\footnotetext{
${ }^{1}$ Assistant Professor, Dept. of Civil Engineering, Univ. of Sistan and Baluchestan, Zahedan, Iran (corresponding author). E-mail: se_mu15@ stu-mail.um.ac.ir

${ }^{2}$ Professor, Dept. of Civil Engineering, Ferdowsi Univ. of Mashhad, Mashhad, Iran. E-mail: esfahani@um.ac.ir

Note. This manuscript was submitted on July 20, 2011; approved on January 31, 2012; published online on February 3, 2012. Discussion period open until March 1, 2013; separate discussions must be submitted for individual papers. This paper is part of the Journal of Composites for Construction, Vol. 16, No. 5, October 1, 2012. (C) ASCE, ISSN 1090-0268/ 2012/5-490-498/\$25.00.
}

strength; however, these bars are more cost-effective in comparison with CFRP bars.

The behavior of concrete beams reinforced with FRP bars is different from that of steel-reinforced concrete beams and is highly dependent on the type of the fiber reinforcement. FRP bars have high tensile strengths and appropriate durability. However, these bars display a linear elastic behavior up to the point of failure and do not demonstrate ductility. The bond between concrete and FRP bars is different from that with steel bars because of the differences in their surface geometries and mechanical characteristics. The bond strength of FRP bars is lower than that of steel bars, and can lead to an increase in the depth of cracking, a decrease in the tension stiffening effect, and consequently an increase the deflection of FRP-reinforced concrete beams relative to steelreinforced concrete beams for an equivalent cross-sectional stiffness of reinforcement. Moreover, FRP-reinforced concrete members have a relatively smaller stiffness factor after cracking because the elastic modulus of FRP bars is typically lower than that of steel bars. For example, the modulus of elasticity of GFRP bars is only $20-25 \%$ of that in steel bars. As a result of their low modulus of elasticity, the deflection criterion may control the design of intermediate and long beams reinforced with GFRP bars. Therefore, the design of FRP-reinforced concrete beams is usually governed by the serviceability limit state requirements (crack width and deflection criteria) rather than ultimate limit state requirements (Newhook et al. 2002). Consequently, a method is needed to predict the expected service load deflections of FRP-reinforced members with a reasonably high degree of accuracy.

In this study, analytical models for predicting the deflection of FRP-reinforced concrete beams are compared with experimental results. This comparison shows a need for reliability analysis of FRP code equations for calculating the deflection. The main objective of this paper is to propose new equations that correlate well with experimental results. Four hundred data points were used to obtain these equations, and in order to minimize the differences 
between the experimental results and the calculated values, optimization by genetic algorithm was conducted.

\section{Analytical Models for Deflection Calculation}

The maximum deflection at the center of a beam in a four-point load system can be calculated by:

$$
\delta_{\max }=\frac{P \cdot L_{a}}{48 E_{c} I_{e}}\left(3 L^{2}-4 L_{a}^{2}\right)
$$

where $L$ is the span of the beam; $P$ is the total concentrated load divided into two concentrated loads $(P / 2)$, each applied at a distance $L_{a}$ from the support; $E_{c}$ is the modulus of elasticity of concrete; and $I_{e}$ is the effective moment of inertia of the beam section after cracking. Since the modulus of elasticity of GFRP bars is lower than that of steel bars, the stiffness of concrete beams reinforced with GFRP bars abruptly decreases when the applied moment exceeds $M_{c r}$. Then, the effective moment of inertia drops to a value slightly greater than $I_{c r}$ after cracking (Alsayed et al. 2000). According to the ACI 318-05 code (2005), the effective moment of inertia suggested by Branson (1965), $I_{e}$, can be determined as follows:

$$
I_{e}=\left(\frac{M_{c r}}{M_{a}}\right)^{3} I_{g}+\left[1-\left(\frac{M_{c r}}{M_{a}}\right)^{3}\right] I_{c r} \leq I_{g}
$$

In Eq. (2), $M_{c r}$ is the cracking moment; $M_{a}$ is the maximum service moment; $I_{c r}$ is the moment of inertia of the cracked transformed section, and $I_{g}$ is the moment of inertia of the gross section neglecting the reinforcement. The contribution of concrete to the tensile stiffness between the cracks of a reinforced concrete member is influenced by the tension stiffening phenomenon. This phenomenon affects the stiffness, deflection and crack width of

Table 1. Different Equations for the Effective Moment of Inertia of

\begin{tabular}{|c|c|}
\hline Reference & Model \\
\hline Faza and Ganga Rao (1992) & $I_{m}=\frac{23 I_{c r} I_{e}}{8 I_{c}+15 I_{L}}$ \\
\hline Benmokrane et al. (1996) & $I_{e}=\left(\frac{M_{c r}}{M_{a}}\right)^{3} \frac{I_{g}}{7}+0.84\left[1-\left(\frac{M_{c r}}{M_{a}}\right)^{3}\right] I_{c r} \leq I_{g}$ \\
\hline ACI 440.1R-03 (2003) & $\begin{array}{c}I_{e}=\left(\frac{M_{c r}}{M_{a}}\right)^{3} \beta_{d} I_{g}+\left[1-\left(\frac{M_{c r}}{M_{a}}\right)^{3}\right] I_{c r} \leq I_{g} \\
\beta_{d}=\alpha_{b}\left(\frac{E_{f}}{E_{s}}+1\right)\end{array}$ \\
\hline Yost et al. (2003) & $\alpha_{b}=0.064\left(\frac{\rho_{f}}{\rho_{f b}}\right)+0.13$ \\
\hline ACI 440.1R-06 (2006) & $\beta_{d}=\frac{1}{5}\left(\frac{\rho_{f}}{\rho_{f b}}\right) \leq 1$ \\
\hline Rafi and Nadjai (2009) & $\begin{array}{c}I_{e}=\left(\frac{M_{c r}}{M_{a}}\right)^{3} \beta_{d} I_{g}+\frac{I_{c r}}{\gamma}\left[1-\left(\frac{M_{c r}}{M_{a}}\right)^{3}\right] \leq I_{g} \\
\gamma=\left(0.0017 \frac{\rho_{f}}{\rho_{f b}}+0.8541\right)\left(1+\frac{E_{f}}{2 E_{s}}\right)\end{array}$ \\
\hline $\begin{array}{l}\text { Alsayed et al. (2000)_- } \\
\text { model B }\end{array}$ & $\begin{array}{c}I_{e}=I_{c r} \\
\text { for } \frac{M_{a}}{M_{c r}}>3 \quad I_{e}=\left[1.4-\frac{2}{15}\left(\frac{M_{a}}{M_{c r}}\right)\right] I_{c r} \text { for } 1<\end{array}$ \\
\hline Bischoff $(2005,2007)$ & $I_{e}=\frac{\frac{M_{a}}{M_{c r}}<3}{1-\left(1-\frac{I_{c r}}{I_{g}}\right)\left(\frac{M_{c r}}{M_{a}}\right)^{2}}$ \\
\hline $\begin{array}{l}\text { Bischoff and Gross } \\
(2011 a, b)\end{array}$ & $\begin{array}{c}I_{e}^{\prime}=\frac{I_{c r}}{1-\gamma\left(1-\frac{I_{c r}}{I_{g}}\right)\left(\frac{M_{c r}}{M_{a}}\right)^{2}} \\
\gamma \text { in four-point flexural beams: } \\
\gamma=\frac{3\left(\frac{L_{a}}{L}\right)-4\left\{4\left(\frac{M_{c r}}{M_{a}}\right)-3\right\}\left(\frac{L_{a}}{L}\right)^{3}}{3\left(\frac{L_{a}}{L}\right)-4\left(\frac{L_{a}}{L}\right)^{3}}\end{array}$ \\
\hline ISIS Canada (2001) & $I_{e}=\frac{I_{T} I_{c r}}{I_{c r}+\left[1-0.5\left(\frac{M_{c r}}{M_{a}}\right)^{2}\right]\left(I_{T}-I_{c r}\right)}$ \\
\hline Hall and Ghali (2000) & $I_{m}=\frac{I_{T} I_{c r}}{\left[I_{T}+\beta_{1} \beta_{2}\left(\frac{M_{c r}}{M_{a}}\right)^{2}\left(I_{c r}-I_{T}\right)\right]}$ \\
\hline
\end{tabular}
FRP-Reinforced Concrete Beams flexural members. The tension stiffening component in Branson's equation [Eq. (2)] depends on the ratio of gross-to-cracked moment of inertia $I_{g} / I_{\mathrm{cr}}$, and increases substantially with $I_{g} / I_{c r}$ ratios greater than 3. Beams reinforced with FRP bars typically have $I_{g} / I_{c r}$ ratios greater than 5. Therefore, Eq. (2) would underestimate the deflections of these beams (Bischoff 2007).

Different models for the effective moment of inertia of FRPreinforced concrete beams are shown in Table 1. Faza and Ganga Rao (1992) derived the average moment of inertia, $I_{m}$, in four-point flexural beams. In this model, the cracking moment of inertia, $I_{c r}$, is used for the middle part of the beam, and the effective moment of inertia, $I_{e}$ [Eq. (2)], is used for the two end parts of the beam.

The effective moments of inertia are generally the same in the models suggested by ACI 440.1R-03 (2003), Yost et al. (2003), and ACI 440.1R-06 (2006). The parameter $\beta_{d}$ accounts for the bond properties and modulus of elasticity of FRP bars in the ACI 440.1R-03 (2003) equation. In this parameter, $E_{f}$ is the elastic modulus of the FRP bars; $E_{s}$ is the elastic modulus of the reinforcing steel bars, and $\alpha_{b}$ is a bond-dependent coefficient. According to the ACI 440.1R-03 (2003) code, the value of $\alpha_{b}$ can be taken as 0.5 for GFRP bars. On the basis of results from 48 GFRP-reinforced concrete beam specimens tested by Yost et al. (2003), $\alpha_{b}$ must be significantly reduced to a value less than the 0.5 recommended by ACI 440.1R-03 (2003). These results also show that this parameter depends on $\rho_{f} / \rho_{f b}$ (Table 1 ), where $\rho_{f}$ is the reinforcement ratio and $\rho_{f b}$ is the balanced reinforcement ratio. Evaluation of experimental results from several studies has resulted in, a new expression for $\beta_{d}$, based on the relative reinforcement ratio, as proposed by ACI 440.1R-06 (2006) and shown in Table 1.

A modification to the ACI 440.1R-06 (2006) method for calculating the effective moment of inertia was proposed by Rafi and Nadjai (2009) for all types of FRP bars. In this model, the coefficient $\beta_{d}$ is similar to the expression used by the ACI 440.1R-06 code (2006). The coefficient $\gamma$ is a relationship obtained by linear regression analysis of the test results (Table 1). Alsayed et al. (2000) proposed two models for the effective moment of inertia based on experimental results. In the first model (model A), the average value of the power $(\mathrm{m})$ for GFRP-reinforced concrete beams can be taken as approximately 5.5, rather than 3 as in Branson's equation. Another model (model B) was suggested by regression analysis of the experimental results of $I_{e} / I_{c r}$ versus $M_{a} / M_{c r}$ for beams reinforced with GFRP bars.

Fundamental concepts of tension stiffening were used by Bischoff $(2005,2007)$ to propose a new expression for the effective moment of inertia, $I_{e}$ (Table 1 ). In this equation, $M_{c r}$ is the cracking moment and $M_{a}$ is the applied load moment of the critical section. $I_{e}$ is conservatively based on the moment of the critical section (where the member stiffness is the lowest). Bischoff and Gross (2011a, b) proposed an equation, for the equivalent moment of inertia, $I_{e}^{\prime}$ which includes an additional factor, $\gamma$, to account for the change of stiffness along the length of beams. They concluded that a reduced cracking moment equal to $80 \%$ of the cracking moment value in the ACI 318-05 (2005) code provides a reasonable estimate of deflection for FRP-reinforced concrete beams using their expression.

Hall and Ghali (2000) have proposed an expression similar to that in the ISIS Canada Design Manual 3 (2001). In these models, $I_{T}$ and $I_{c r}$ are the moments of inertia for uncracked and fully cracked transformed sections, respectively; $\beta_{1}$ is a coefficient characterizing the bond properties of the reinforcing bars and is equal to 1.0 for ribbed bars and 0.5 for smooth bars; and $\beta_{2}$ is a coefficient representing the type of loading and is equal to 0.8 for first loading and 0.5 for sustained or cyclic loading. CSA S806-02 (2002) uses a simple equation, derived by Razaqpur et al. (2000), for calculating 
the deflection of simply supported four-point bending FRPreinforced concrete beams as follows:

$$
\delta_{\max }=\frac{P \cdot L_{a}}{48 E_{c} I_{c r}}\left(3 L^{2}-4 L_{a}^{2}-8\left(1-\frac{I_{c r}}{I_{g}}\right)\left(\frac{M_{c r}}{M_{a}}\right)^{3} L_{a}^{2}\right)
$$

The CSA S806-02 (2002) approach is based on an assumption that the moment-curvature relationship of a cracked FRPreinforced member remains linear under increasing load, which ignores the tension-stiffening effect. Rasheed et al. (2004) derived an analytical solution to predict the load-deflection response of concrete beams reinforced with FRP bars. This solution is based on a bilinear moment-curvature relationship. The results of this study indicate that an increase in tension reinforcement stiffness leads to stress nonlinearity in the beam's compression zone, causing the value of $I_{e}$ to fall below that of $I_{c r}$ (Rasheed et al. 2004).

Abdalla (2002) tested 15 different concrete members (beams and slabs) reinforced with CFRP and two types of GFRP bars. Experimental deflections were used to evaluate various models of deflection calculation. According to Abdalla (2002), the ACI 440.1R-03 (2003) guidelines for design of FRP-reinforced concrete members underestimate deflections when compared to the measured values. However, deflections estimated by the ISIS Canada Design Manual 3 (2001) approach are in good agreement with the experimental results.

Mota et al. (2006) conducted a statistical analysis on the efficiency of different methods for deflection estimation, in which 197 beams and slabs were analyzed to find an accurate and conservative equation for estimating the deflection of FRP-reinforced concrete members. The analysis showed that the accuracy of the predicted deflection is highly dependents on the accuracy of the calculated cracking moment and loading levels. At the service load level, the equation proposed by Yost et al. (2003) was sufficiently accurate and conservative for predicting the deflection of GFRP-RC members, while the equation in the ISIS Canada Design Manual 3 (2001) was the most accurate and conservative equation for predicting the deflection of CFRP-RC members (Mota et al. 2006).

\section{Proposed Models}

In this paper, a wide range of test data including four hundred data points is used. These data points were obtained from loaddisplacement relationships of 64 FRP-reinforced concrete beam specimens. Nine of the specimens were tested by the authors. Details of different experimental studies are summarized in Table 2. In the experimental data points, a wide range of different parameters such as concrete strength $\left(f_{c}^{\prime}=20 \mathrm{MPa}-79.7 \mathrm{MPa}\right)$, modulus of elasticity of FRP bars $\left(E_{f}=26 \mathrm{GPa}-147 \mathrm{GPa}\right)$, relative reinforcement ratio $\left(\rho_{f} / \rho_{f b}=0.51-7.75\right)$, and level of loading $\left(M_{c r} / M_{a}=0.1-0.97\right)$ were evaluated. Using the values of mid-span displacement and its corresponding load, the experimental values of effective moment of inertia can be calculated using Eq. (4) as follows:

$$
\left(I_{e}\right)_{\exp }=\frac{P_{\exp } L_{a}}{48 E_{c} \delta_{\exp }}\left(3 L^{2}-4 L_{a}^{2}\right)
$$

where $P_{\exp }$ is the experimental load and $\delta_{\exp }$ is the experimental midspan displacement corresponding to $P_{\exp }$.

\section{Proposed Effective Moment of Inertia (Model A)}

Similarly to Branson's equation [Eq. (2)], the effective moment of inertia can be calculated using Eq. (5) as follows:
Table 2. Experimental Studies of FRP Reinforced Concrete Beams

\begin{tabular}{lcc}
\hline Study & $\begin{array}{c}\text { Number of beam } \\
\text { specimens }\end{array}$ & $\begin{array}{r}\text { Number of } \\
\text { data points }\end{array}$ \\
\hline Alsayed (1998) & 3 & 14 \\
Pecce et al. (2000) & 2 & 9 \\
Hall (2000) & 2 & 16 \\
Alsayed et al. (2000) & 4 & 15 \\
Abdalla (2002) & 6 & 36 \\
Toutanji and Deng (2003) & 3 & 21 \\
Yost et al. (2003) & 16 & 77 \\
Rafi et al. (2008) & 2 & 16 \\
Rafi and Nadjai (2009) & 8 & 67 \\
Barris et al. (2009) & 2 & 15 \\
Oh et al. (2009) & 7 & 36 \\
Current study & 9 & 78 \\
Total & 64 & 400 \\
\hline
\end{tabular}

$$
\begin{aligned}
\left(I_{e}\right)_{\exp } & =\left(\frac{M_{c r}}{M_{a}}\right)^{m} I_{g}+\left[1-\left(\frac{M_{c r}}{M_{a}}\right)^{m}\right] I_{c r} \leq I_{g} \\
& \Rightarrow \frac{\left(I_{e}\right)_{\exp }-I_{c r}}{I_{g}-I_{c r}}=\left(\frac{M_{c r}}{M_{a}}\right)^{m}
\end{aligned}
$$

Parameter $m$ can be obtained using $\left(I_{e}\right)_{\exp }$ and $M_{c r} / M_{a}$ values for every experimental result at any level of loading as follows:

$$
m=\frac{\log \left(\frac{\left(I_{e}\right)_{\exp }-I_{c r}}{I_{g}-I_{c r}}\right)}{\log \left(\frac{M_{c r}}{M_{a}}\right)}
$$

The $m$ values obtained using Eq. (6) versus $M_{c r} / M_{a}$ and $\rho_{f} / \rho_{f b}$ relationships are presented in Figs. 1 and 2, respectively. As shown in Fig. 1, the value of $m$ decreases with an increase in level of loading (a decrease in $M_{\mathrm{cr}} / M_{a}$ value). Also, according to Fig. 2, the power $m$ is dependent on the relative reinforcement ratio $\left(\rho_{f} / \rho_{f b}\right)$.

According to Branson's equation [Eq. (2)], the effective moment of inertia, $I_{e}$, at different levels of loading, interpolates between the moment of inertia of an uncracked gross concrete section, $I_{g}$, and the moment of inertia of a transformed cracked section, $I_{c r}$. In Eq. (2), the effective moment of inertia is never less than the cracked moment of inertia. In beams reinforced with FRP bars, the effective moment of inertia approaches the cracked moment of inertia after cracking occurs. As shown in Figs. 3 and 4, at high levels of loading (low $M_{c r} / M_{a}$ ) and reinforcement ratios (high $\rho_{f} / \rho_{f b}$ ), the effective moment of inertia becomes less than

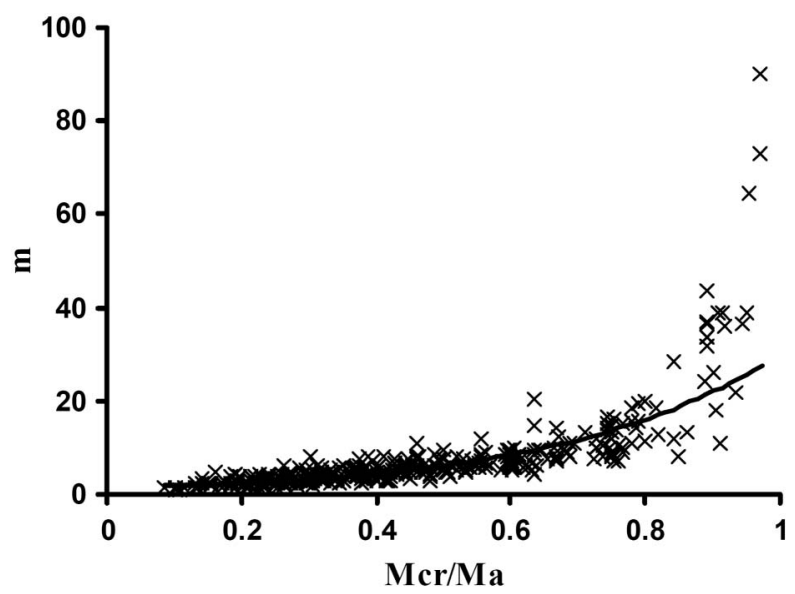

Fig. 1. Relationships of m versus $M_{c r} / M_{a}$ values 


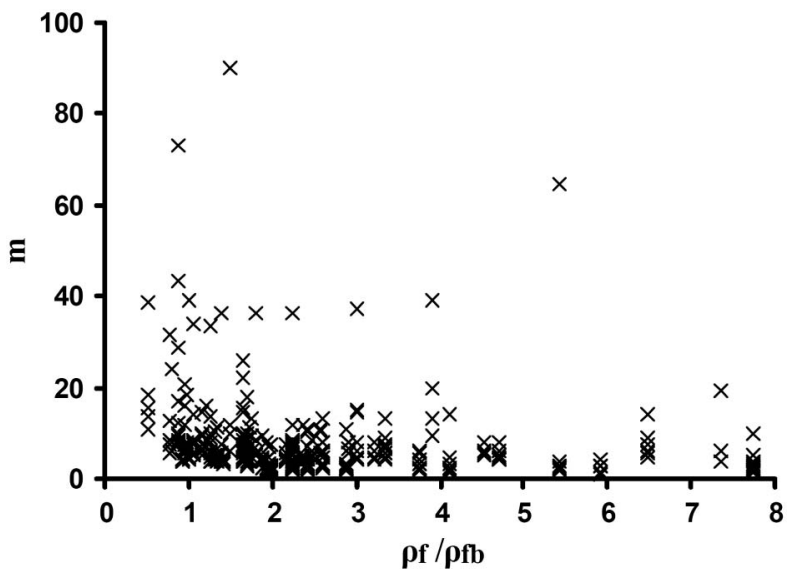

Fig. 2. Relationships of $\mathrm{m}$ versus $\rho_{f} / \rho_{f b}$ values

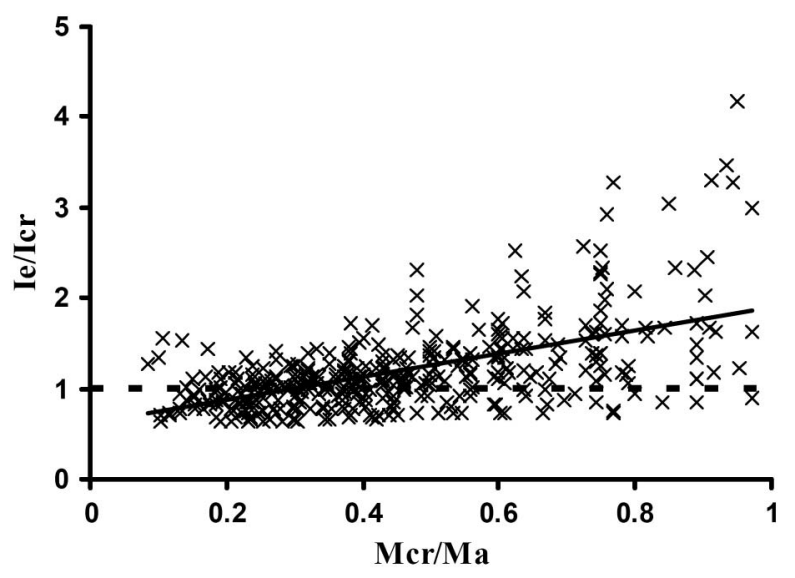

Fig. 3. Relationships of $I_{e} / I_{c r}$ versus $M_{c r} / M_{a}$ values

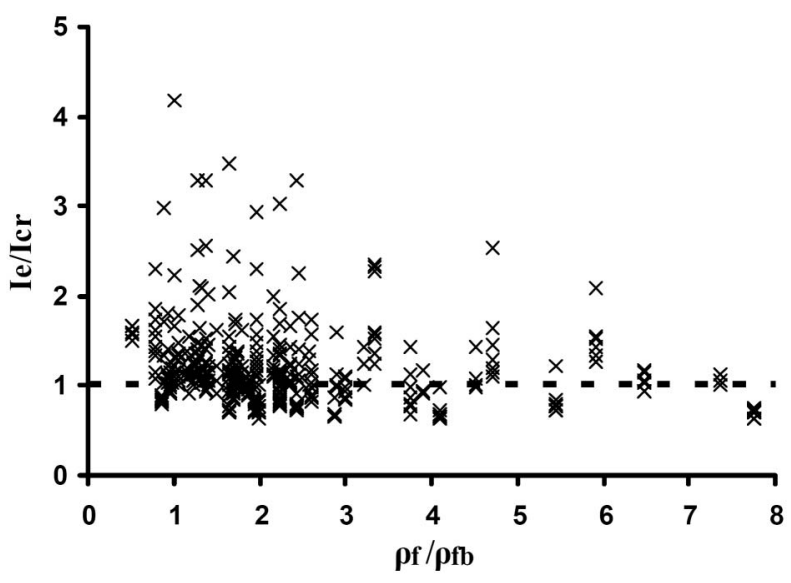

Fig. 4. Relationships of $I_{e} / I_{c r}$ versus $\rho_{f} / \rho_{f b}$ values

the cracked moment of inertia because of nonlinearity of concrete in the compressive zone. Thus, the two parts of Branson's equation should be multiplied by reduction coefficients, the second part outweighing the first part in concrete beams reinforced with FRP bars.

According to the experimental results and optimization by genetic algorithm, Branson's equation [Eq. (2)] is modified so that the predicted values of deflection approach the experimental values. This is the algorithm that was used to evaluate the effects of several parameters and to re-evaluate the power in Branson's equation. The effects of elastic modulus of FRP bars, reinforcement ratio, and level of loading on the power $m$ in Branson's equation are taken into account in this study. The influence of different parameters is introduced by the coefficients $X_{1}-X_{6}$ in the following equations:

$$
\left(I_{e}\right)_{\text {theo }}=X_{5}\left(\frac{M_{c r}}{M_{a}}\right)^{m} I_{g}+X_{6}\left[1-\left(\frac{M_{c r}}{M_{a}}\right)^{m}\right] I_{c r} \leq I_{g}
$$

The power of $m$ is calculated using Eq. (8):

$$
m=X_{1}+X_{2} \frac{\rho_{f}}{\rho_{f b}}+X_{3} \frac{M_{c r}}{M_{a}}+X_{4} \frac{E_{f}}{E_{s}}
$$

In order to calculate the coefficients $X_{1}-X_{6}$ in Eqs. (7) and (8), the difference between experimental deflection and the deflection value predicted by Eq. (7) is defined as an optimization objective function. The optimization variables $\left(X_{1}-X_{6}\right)$, which determine the influence of different parameters in beam deflection, are calculated by minimizing the objective function using the genetic algorithm method. The objective function is defined by Eq. (9).

$$
e=\left|\delta_{\exp }-\delta_{\text {cal }}\right|
$$

The genetic algorithm method (GA) is an optimization and search technique based on the principles of genetics and natural selection. The GA creates a number of answers which are called the population. If a predicted deflection by an answer is closer to the experimental deflection, it will have a higher value of fitness. After evaluating the fitness of all population individuals, the more qualified individuals from the population are selected to create the next generation, which usually has greater values of fitness than the previous one. Subsequently, crossover and mutation operations are performed on the individuals selected to generate the next population. This algorithm continues until convergence criteria are satisfied, and the individual having the greatest value of fitness in the last generation is the best answer. Different solutions for optimization show that 500 as the size of population and 5000 as the iteration number are sufficient to achieve an optimized answer. The values of $X_{1}-X_{6}$ obtained by this optimization determine the influence of different parameters in the proposed model $A$ as follows:

$$
\begin{aligned}
\left(I_{e}\right)_{\text {Model A }} & =0.15\left(\frac{M_{c r}}{M_{a}}\right)^{m} I_{g}+0.89\left[1-\left(\frac{M_{c r}}{M_{a}}\right)^{m}\right] I_{c r} \leq I_{g} \\
m & =0.66-0.3 \frac{\rho_{f}}{\rho_{f b}}+1.94 \frac{M_{c r}}{M_{a}}+4.64 \frac{E_{f}}{E_{s}}
\end{aligned}
$$

\section{Proposed Effective Moment of Inertia (Model B)}

This model is similar to the previous one (model A), and is also formulated using an optimization by the genetic algorithm method. However, optimization variables $X_{1}-X_{6}$ are obtained by minimizing the error between the effective moments of inertia predicted using Eq. (7) and experimental values. The objective function is defined by the following equation:

$$
e=\left|\left(I_{e}\right)_{\exp }-\left(I_{e}\right)_{\text {theo }}\right|
$$

Model B is defined by Eqs. (13) and (14) as follows: 
Table 3. Ultimate Loads and Details of Test Specimens

\begin{tabular}{|c|c|c|c|c|c|c|c|}
\hline $\begin{array}{l}\text { Specimen } \\
\text { number }\end{array}$ & $f_{c}^{\prime}(\mathrm{MPa})$ & $\begin{array}{c}\text { Longitudinal } \\
\text { reinforcement (GFRP) }\end{array}$ & $d(\mathrm{~mm})$ & $A_{f}\left(\mathrm{~mm}^{2}\right)$ & $\rho_{f}$ & $\left(\rho_{f} / \rho_{\mathrm{fb}}\right)$ & $\begin{array}{c}\text { Experimental ultimate } \\
\text { load }(\mathrm{kN}) \\
\end{array}$ \\
\hline B1 & 20 & $2 \phi 10$ & 165 & 142 & 0.0057 & 1.64 & 33.5 \\
\hline B2 & 20 & $2 \phi 16+1 \phi 10$ & 165 & 471 & 0.0190 & 5.44 & 57.0 \\
\hline B3 & 20 & $3 \phi 16+1 \phi 10$ & 165 & 671 & 0.0271 & 7.75 & 56.4 \\
\hline B4 & 38 & $2 \phi 10$ & 165 & 142 & 0.0057 & 0.87 & 32.9 \\
\hline B5 & 38 & $2 \phi 16+1 \phi 10$ & 165 & 471 & 0.0190 & 2.88 & 86.0 \\
\hline B6 & 38 & $3 \phi 16+1 \phi 10$ & 165 & 671 & 0.0271 & 4.11 & 95.4 \\
\hline B7 & 64 & $2 \phi 10$ & 165 & 142 & 0.0057 & 0.51 & 38.0 \\
\hline B8 & 64 & $2 \phi 16+1 \phi 10$ & 165 & 471 & 0.0190 & 1.70 & 96.4 \\
\hline B9 & 64 & $3 \phi 16+1 \phi 10$ & 165 & 671 & 0.0271 & 2.42 & 112.1 \\
\hline
\end{tabular}

$$
\begin{aligned}
\left(I_{e}\right)_{\text {Model B }} & =0.17\left(\frac{M_{c r}}{M_{a}}\right)^{m} I_{g}+0.94\left[1-\left(\frac{M_{c r}}{M_{a}}\right)^{m}\right] I_{c r} \leq I_{g} \\
m & =1.69-0.51 \frac{\rho_{f}}{\rho_{f b}}+1.77 \frac{M_{c r}}{M_{a}}+6.67 \frac{E_{f}}{E_{s}}
\end{aligned}
$$

\section{Test Specimens}

Nine beam specimens with a total length of $2300 \mathrm{~mm}$, width of $150 \mathrm{~mm}$, depth of $200 \mathrm{~mm}$, and shear span of $700 \mathrm{~mm}$ were manufactured and tested. Three different concrete mix designs with compressive strengths of 20,38, and $64 \mathrm{MPa}$ were used for the beam specimens. Two 10-mm-diameter steel bars were used as compression reinforcement. The steel stirrups had a diameter of $8 \mathrm{~mm}$ and were spaced at $80 \mathrm{~mm} o / c$ for all specimens to provide shear strength. The structural details and ultimate experimental loads of specimens are shown in Table 3.

The GFRP bars used for the specimens were sand-coated, having an ultimate tensile strength and elastic modulus of $700 \mathrm{MPa}$ and $41 \mathrm{GPa}$, respectively. Test specimens had three different concrete compressive strengths and reinforcement ratios that produced a wide range of relative reinforcement ratios, $\rho_{f} / \rho_{f b}$, between 0.51 and 7.75. Using the results from these specimens, the effect of $\rho_{f} / \rho_{f b}$ on the proposed equations for deflection prediction can be considered.

\section{Experimental Work}

All specimens with an effective span length of $2000 \mathrm{~mm}$ were subjected to a four-point flexural test. Two concentrated loads were applied to the specimens by means of a hydraulic jack and a spreader beam (Fig. 5). A load cell was placed directly under the hydraulic jack and on top of the spreader beam to transfer the load increments to a data logger acquisition system. A linear variable displacement transducer (LVDT) was placed at the center of the specimens to transfer the mid-span displacement values to the data logger. The load increments and the corresponding displacements could be read directly from the data logger. At the supports, load was transferred through a steel rod and bearing plate. This configuration was selected to simulate a pin-roller support system. The midspan deflection for each specimen was obtained at different levels of loading. The cracks of the specimens were mapped and test observations were recorded during loading and at the time of failure. Fig. 6 shows the crack growth and the failure state of specimen B7.

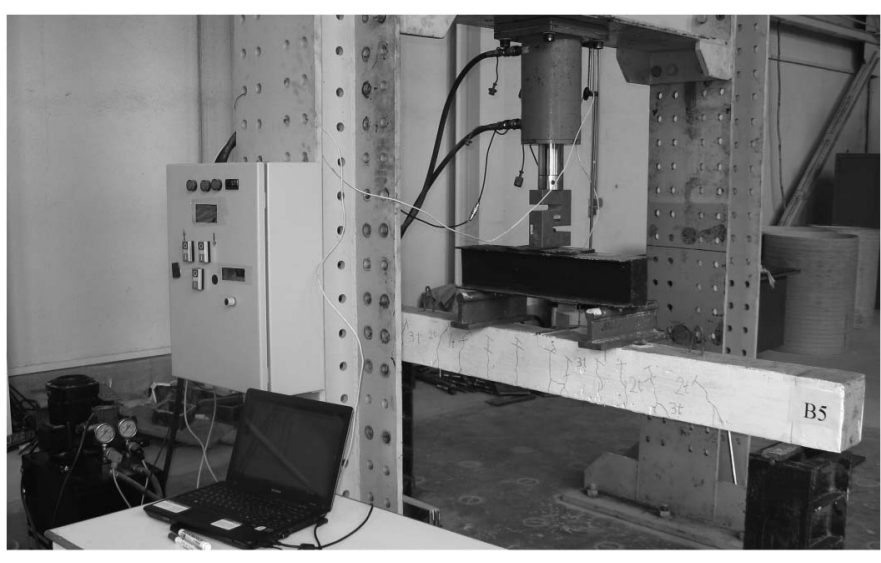

Fig. 5. Details of test apparatus

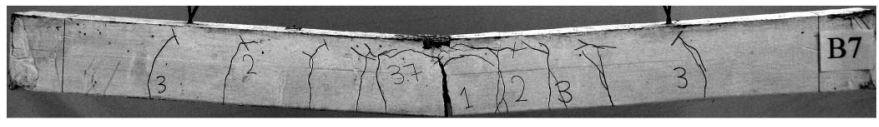

Fig. 6. Crack growth and failure state of specimen B7

\section{Comparison of Analytical and Experimental Results}

The flexural capacity of FRP-reinforced concrete beams is dependent on the mode of failure. If the reinforcement ratio is less than the balanced ratio $\left(\rho_{f}<\rho_{f b}\right)$, the section is under-reinforced and failure by FRP rupture occurs. If the reinforcement ratio is greater than the balanced ratio $\left(\rho_{f}>\rho_{f b}\right)$, the section is over-reinforced and failure by concrete crushing occurs. Studies show that a beam experiencing an FRP rupture exhibits less ductility than one experiencing concrete crushing (Newhook et al. 2002; ACI 440.1R-06 2006).

All specimens, except for specimen B7, failed by concrete crushing. Comparison of the experimental results shows that the effect of reinforcement ratio on the deflection of FRP-reinforced concrete beams is significant. Deflection increases with a decrease in reinforcement ratio, especially at a higher level of loading. With an increase in concrete compressive strength, the cracking moment of the beam increases and fewer cracks appear under the same level of loading. Consequently, the deflection decreases with an increase in concrete compressive strength. However, the effect of concrete compressive strength on deflection reduction is not considerable at high reinforcement ratios.

For FRP-reinforced sections, ACI 440.1R-06 (2006) requires that the nominal moment strength multiplied by the strength reduction factor $(\varphi)$ is greater than or equal to the moment at service, $M_{s}$, 

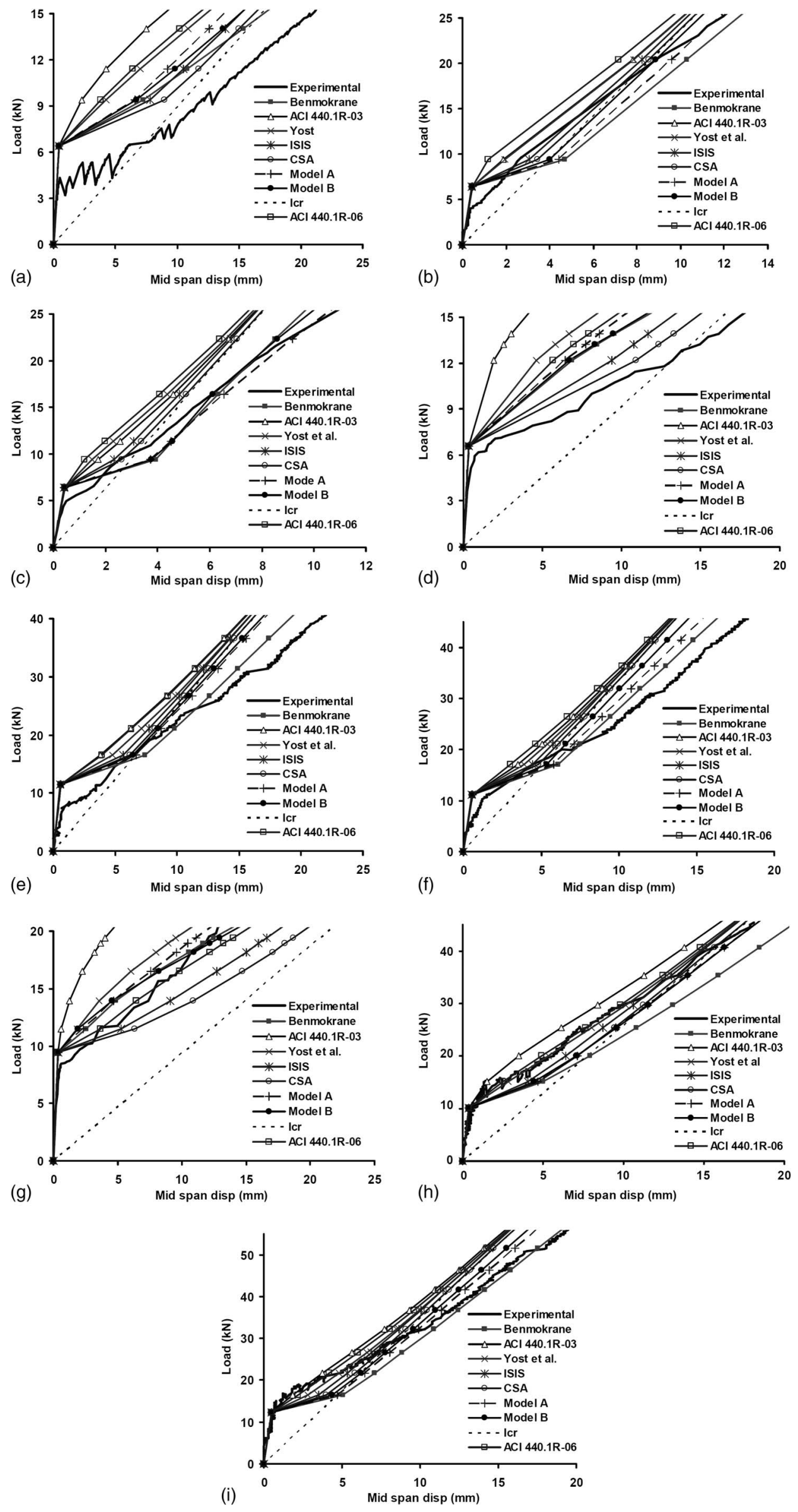

Fig. 7. Comparison of analytical deflections with experimental values 


\begin{tabular}{|c|c|c|c|c|c|c|}
\hline \multirow[b]{2}{*}{ Reference } & \multicolumn{2}{|r|}{ Total } & \multicolumn{2}{|c|}{$\begin{array}{l}\text { High levels of loading } \\
\qquad\left(M_{a} / M_{c r} \geq 4\right)\end{array}$} & \multicolumn{2}{|c|}{$\begin{array}{l}\text { High reinforcement ratios } \\
\left(\rho_{f} / \rho_{f b} \geq 3\right)\end{array}$} \\
\hline & Mean & Standard deviation & Mean & Standard deviation & Mean & Standard deviation \\
\hline Branson (1965) and ACI 318-05 (2005) & -0.718 & 0.620 & -0.163 & 0.216 & -0.528 & 0.406 \\
\hline ACI $440.1 \mathrm{R}(2003)$ & -0.498 & 0.498 & -0.136 & 0.217 & -0.344 & 0.301 \\
\hline ACI 440.1R (2006) & -0.283 & 0.342 & -0.118 & 0.224 & -0.460 & 0.364 \\
\hline Benmokrane et al. (1996) & 0.111 & 0.970 & 0.076 & 0.220 & 0.142 & 0.274 \\
\hline Yost et al. (2003) & -0.038 & 0.275 & -0.098 & 0.222 & -0.111 & 0.260 \\
\hline ISIS Canada (2001) & -0.011 & 0.281 & -0.109 & 0.223 & -0.084 & 0.313 \\
\hline Hall and Ghali (2000) & -0.112 & 0.280 & -0.119 & 0.223 & -0.165 & 0.307 \\
\hline Faza and Ganga Rao (1992) & -0.061 & 0.277 & -0.116 & 0.219 & -0.109 & 0.291 \\
\hline Alsayed et al. (2000)—model A & -0.306 & 0.540 & -0.094 & 0.222 & -0.227 & 0.355 \\
\hline Alsayed et al. (2000)—model B & -0.101 & 0.313 & -0.092 & 0.222 & -0.180 & 0.325 \\
\hline Bischoff (2007) & -0.199 & 0.340 & -0.126 & 0.224 & -0.229 & 0.329 \\
\hline Bischoff and Gross (2011) & -0.364 & 0.388 & -0.155 & 0.224 & -0.392 & 0.365 \\
\hline Rafi and Nadjai (2009) & -0.297 & 0.341 & -0.113 & 0.214 & -0.495 & 0.348 \\
\hline CSA-S806 (2002) & 0.025 & 0.276 & -0.095 & 0.223 & -0.067 & 0.312 \\
\hline Proposed equation-model A & -0.029 & 0.282 & -0.056 & 0.155 & -0.001 & 0.208 \\
\hline Proposed equation-model B & -0.007 & 0.276 & -0.075 & 0.178 & -0.040 & 0.203 \\
\hline
\end{tabular}

multiplied by an appropriate load factor. The strength reduction factor $(\varphi)$ is between 0.55 and 0.65 for FRP-reinforced concrete members. Considering an average load factor of 1.4 , the service load is $\varphi / 1.4$ times the ultimate load or approximately $40-46 \%$ of the ultimate load.

Figs. 7(a-i) show the values of experimental and analytical deflections for specimens B1-B9 at the serviceability limit state. In specimens B2, B3, B5, and B6, which have high reinforcement ratios, the deflections obtained according to ACI 440.1R-06 (2006) provisions have the smallest values. According to Figs. 7(a-i), the deflections obtained according to ACI 440.1R-03 (2003) and ACI 440.1R-06 (2006) provisions have the smallest values. The ACI 440.1R-06 (2006) code generates more accurate results for specimens with lower relative reinforcement ratios $\left(\rho_{f} / \rho_{f b}<2.5\right)$ compared to results generated using the ACI 440.1R-03 (2003) code. Figs. 7(a-i) show good agreement between the experimental deflections and those calculated using the proposed models (A and B) as compared with those predicted by the ACI 440.1R-03 (2003), ACI 440.1R-06 (2006), and Yost et al. (2003) equations. In addition, for specimens with values of $\rho_{f} / \rho_{f b}$ greater than 2 , the proposed models (A and B) generate a more accurate result as compared with those obtained using the ISIS Canada Design Manual 3 (2001). It is interesting that the deflections calculated using some previous methods are more consistant with one another at high levels of loading and reinforcement ratios. This occurs in the methods in which minimum effective moments of inertia, $I_{e}$, are equal to the cracked moments of inertia, $I_{c r}$. The effective moments of inertia at high loading levels and relative reinforcement ratios are closer to the constant value of $I_{c r}$ using these methods, while experimental effective moments of inertia are less than $I_{c r}$. The advantage of the proposed models is their ability to more accurately estimate the effective moment of inertia at values less than that of $I_{c r}$. Results show that the ISIS Canada Design Manual (2001) and the CSA S806-02 (2002) code provide more conservative estimates of deflection than the ACI 440.1R-03 (2003) and ACI 440.1R-06 (2006) codes. Figs. 7(b, c, and f) show that in specimens B2, B3, and B6which have high relative reinforcement ratios-the results of proposed model A are more reliable than those of model B. As shown in Figs. 7(d and g), the results of model B are more accurate than those of model $\mathrm{A}$ in specimens having relative reinforcement ratios $\left(\rho_{f} / \rho_{f b}\right)$ less than one. Several codes recommended that the value of $\rho_{f} / \rho_{f b}$ be greater than one to prevent FRP rupture failure.

A statistical comparison of the log transformed ratio of calculated deflection with experimental value $\left(\delta_{\text {cal }} / \delta_{\exp }\right)$ is performed to evaluate the accuracy of the proposed and previous methods of deflection calculation. The average and standard deviation for all data, high levels of loading $\left(M_{c r} / M_{a} \leq 0.25\right)$, and high relative reinforcement ratios $\left(\rho_{f} / \rho_{f b} \geq 3\right)$ are shown in Table 4 . These results show that the deflection prediction developed using the proposed equations, in terms of mean value and standard deviation, is satisfactory. As shown in Table 4, the mean value and standard deviation of $\operatorname{Ln}\left(\delta_{\text {cal }} / \delta_{\text {exp }}\right)$ at model $\mathrm{A}$ are -0.056 and 0.155 , respectively, at high levels of loading. In addition, these values are -0.001 and 0.208 at high relative reinforcement ratios. Therefore, the proposed model $\mathrm{A}$, at high levels of loading and relative reinforcement ratios, is more accurate than other models. Model B, with an average of -0.007 and a standard deviation of 0.276 , predicts the deflection of beams accurately with the least scatter for all data. As shown in Table 4, the ACI 440.1R-06 (2006) equationwith an average of -0.283 - underestimates the deflection of beams considerably. The mean and standard deviation values predicted by Yost et al. (2003), the CSA S806-02 (2002) code, and ISIS Canada Design Manual 3 (2001) are -0.038 and 0.275, 0.025 and 0.276 , and -0.011 and 0.281 , respectively. Therefore, these models satisfactorily predict the deflection.

Figs. 8(a-d) show a comparison of the deflection values calculated the experimental values using different equations. The deflections predicted using the equation proposed by Bischoff and Gross (2011a, b) are underestimated, whereas the values calculated using the equation proposed by Benmokrane et al. (1996) are overestimated. Additionally, the results from the proposed models (A and B), ISIS Canada Design Manual 3 (2001), and Yost et al. (2003) show good agreement with the experimental deflections.

\section{Summary and Conclusion}

The objective of this paper was to compare experimental and analytical deflections of concrete beams reinforced with FRP bars. On the basis of experimental results and Branson's equation, new equations were proposed for the effective moment of inertia in concrete beams reinforced with FRP bars. These equations were derived 


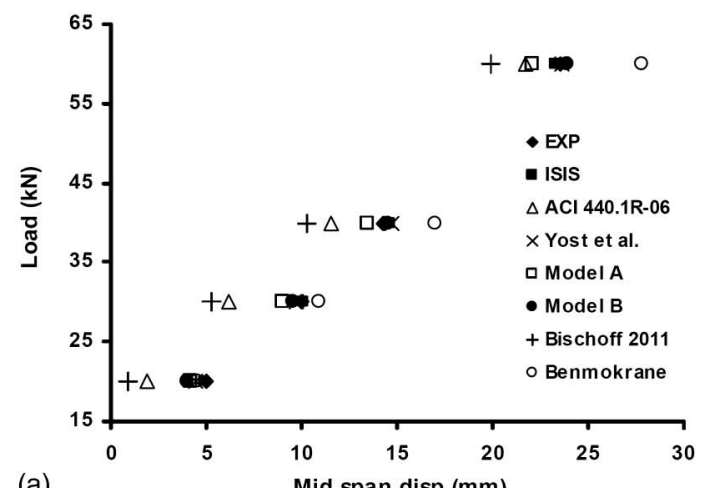

(a)
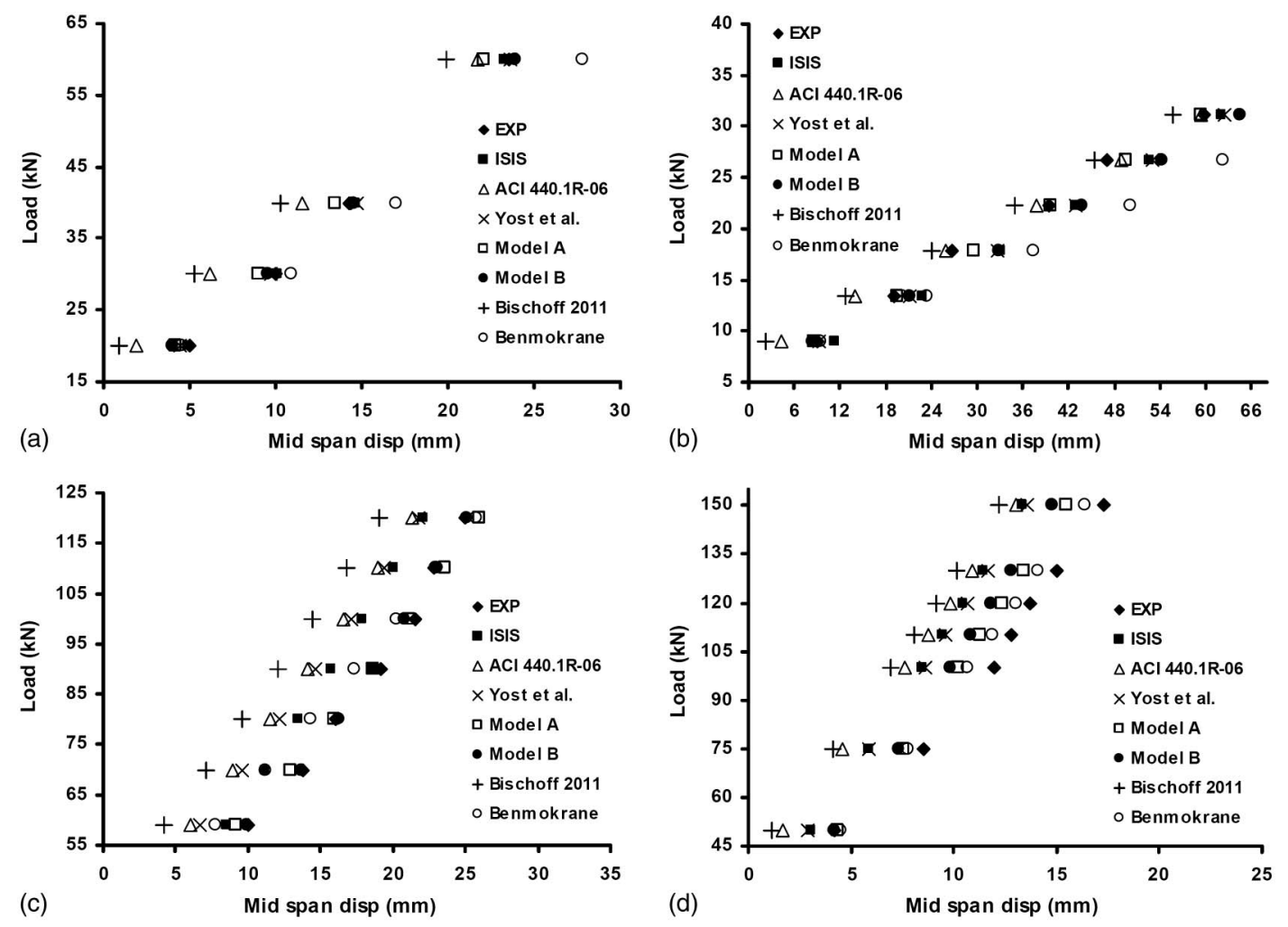

Fig. 8. Comparison of analytical deflections with experimental values in different studies: (a) Specimen IV tested by Alsayed et al. (2000), GFRP; (b) Specimen 3NL tested by Yost et al. (2003), GFRP; (c) Specimen L0.2 tested by Abdalla (2002), CFRP; (d) Specimen L0.4 tested by Abdalla (2002), CFRP

such that the differences between experimental responses and calculated values are minimized using genetic algorithm optimization. In the experimental part of the study, nine beam specimens with different concrete compressive strengths and reinforcement ratios were manufactured and tested. A number of beam specimens tested by other researchers were also considered. In the analytical part of the study, 400 experimental values of midspan displacement extracted from load versus midspan displacement relationships of 64 concrete beam specimens reinforced with FRP bars, were examined. The variable parameters included type of reinforcing bar (carbon, glass, aramid), elastic modulus of FRP bars, relative reinforcement ratio $\left(\rho_{f} / \rho_{f b}\right)$, and different levels of loading. Therefore, a variety of effective parameters were considered in the analysis and appropriate equations for deflection prediction were proposed. Comparison of the experimental results with the values calculated using the proposed equations and other analytical models resulted in the following conclusions:

1. Results show that deflection values calculated using the ACI 440.1R-06 (2006) code are more accurate than those predicted using the ACI 440.1R-03 (2003) code for specimens with lower reinforcement ratios. However, the results of the ACI 440.1R-06 (2006) code are not satisfactory for specimens with higher reinforcement ratios.

2. According to the experimental results, the reinforcement ratio and elastic modulus of FRP bars are the most significant variables for calculating the deflection. The effects of both aforementioned variables are considered in the equation proposed by Yost et al. (2003). The deflections estimated using this model are more accurate than those predicted using the ACI 440.1R-03 (2003) and ACI 440.1R-06 (2006) provisions.

3. The ACI 440.1R-03 (2003) and ACI 440.1R-06 (2006) codes underestimate deflections of concrete beams reinforced with
FRP bars. Moreover, deflections calculated using the CSA S806-02 (2002) code are conservative.

4. The proposed equations account for the most effective parameters such as modulus of elasticity of FRP bars, relative reinforcement ratio, and levels of loading for calculating the deflection. The influences of the aforementioned parameters were determined through optimization using the genetic algorithm method. The values predicted using the proposed equations correlate well with the experimental values.

5. The proposed equations can better predict deflection when effective moment of inertia is less than $I_{c r}$, especially at high levels of loading and reinforcement ratios.

6. Proposed models A and B, the formula suggested by Yost et al. (2003), the CSA S806-02 (2002) equation, and the ISIS Canada Design Manual 3 (2001) expression produce the best average and standard deviation of $\operatorname{Ln}\left(\delta_{\text {cal }} / \delta_{\text {exp }}\right)$ values compared with other methods. The values obtained using proposed model A correlate well with experimental results, especially in cases with high levels of loading and high reinforcement ratios.

\section{Notation}

The following symbols are used in this paper:

$A_{f}=$ cross sectional area of longitudinal tensile FRP bars;

$d=$ distance from extreme compression fiber to center of reinforcing bar;

$E_{c}=$ elastic modulus of concrete;

$E_{f}=$ elastic modulus of FRP bars;

$E_{s}=$ elastic modulus of Steel bars;

$f_{c}^{\prime}=$ concrete compressive strength; 
$I_{e}=$ effective moment of inertia;

$I_{g}=$ moment of inertia of the gross section;

$I_{c r}=$ cracked moment of inertia;

$L_{a}=$ shear span of beam;

$M_{a}=$ applied moment;

$M_{c r}=$ cracking moment;

$P=$ total point load;

$P_{\exp }=$ measured point load;

$\delta_{\text {exp }}=$ measured mid-span deflection;

$\rho_{f}=$ FRP reinforcement ratio; and

$\rho_{f b}=$ FRP reinforcement ratio producing balanced strain conditions.

\section{References}

Abdalla, H. A. (2002). "Evaluation of deflection in concrete members reinforced with fiber reinforced polymer (FRP) bars." Compos. Struct., 56(1), 63-71.

ACI Committee 318. (2005). "Building Code Requirements for Reinforced Concrete and Commentary." ACI 318R-05, American Concrete Institute (ACI), Farmington Hills, Mich.

ACI Committee 440. (2003). "Guide for the design and construction of concrete reinforced with FRP bars." ACI 440.1R-03, American Concrete Institute (ACI), Farmington Hills, Mich.

ACI Committee 440. (2006). "Guide for the Design and Construction of Concrete Reinforced with FRP Bars." ACI 440.1R-06, American Concrete Institute (ACI), Farmington Hills, Mich.

Alsayed, S. H. (1998). "Flexural behavior of concrete beams reinforced with GFRP bars." Cem. Concr. Compos., 20(1), 1-11.

Alsayed, S. H., Al-Salloum, Y. A., and Almusallam, T. H. (2000). "Performance of fiber reinforced plastic bars as a reinforcing material for concrete structures." Compos. Part B, 31(6-7), 555-567.

Barris, C., Torres, L., Turon, A., Baena, M., and Catalan, A. (2009). "An experimental study of the flexural behavior of GFRP RC beams and comparison with prediction models." Compos. Struct., 91(3), 286-295.

Benmokrane, B., Chaallal, O., and Masmoudi, R. (1996). "Flexural response of concrete beams reinforced with FRP reinforcing bar." ACI Struct. J., 93(1), 46-55.

Bischoff, P. H. (2005). "Reevaluation of deflection prediction for concrete beams reinforced with steel and fiber reinforced polymer bars." J. Struct. Eng., 131(5), 752-767.

Bischoff, P. H. (2007). "Deflection calculation of FRP reinforced concrete beams based on modifications to the existing Branson equation." J. Compos. Constr., 11(1), 4-14.

Bischoff, P. H., and Gross, S. P. (2011a). "Design approach for calculating deflection of FRP reinforced concrete." J. Compos. Constr., 15(4), 490-499.

Bischoff, P. H., and Gross, S. P. (2011b). "Equivalent moment of inertia based on integration of curvature." J. Compos. Constr., 15(3), 263-273.

Branson, D. E. (1965). "Instantaneous and Time-dependent deflections of simple and continuous reinforced concrete beams." HPR Report No. 7,
Part 1, Alabama Highway Dept., Bureau of Public Roads, AL, (Dept. of Civil Engineering and Auburn Research Foundation, Auburn Univ., Aug. 1963).

Canadian Standard Association (CSA). (2002). "Design and construction of building components with fiber-reinforced polymers." Concrete Design Handbook: Canadian Standard S806-02, CSA, Toronto, Ontario.

Faza, S. S., and Ganga Rao, H. V. S. (1992). "Pre- and post-cracking deflection behavior of concrete beams reinforced by fiber reinforced plastic rebars." Proc., First International Conference on the Use of Advanced Composite Materials in Bridges and Structures, Canadian Society for Civil Engineering, Montreal, 151-160.

Hall, T. S. (2000). "Deflection of concrete members reinforced with fiber reinforced polymer (FRP) bars." M.S thesis, Dept. of Civil Engineering, Univ. of Calgary, Calgary, Alberta.

Hall, T., and Ghali, A. (2000). "Long-term deflection prediction of concrete members reinforced with glass fiber reinforced polymer bars." Can. J. Civil Eng., 27(5), 890-898.

ISIS Canada Corporation. (2001). "Reinforcing concrete structures with fiber reinforced polymers." ISIS Canada: Design Manual No.3, The Canadian Network of Centers of Excellence on Intelligent Sensing for Innovative Structures, Winnipeg, Manitoba, Canada.

Mota, C., Alminar, S., and Svecova, D. (2006). "Critical review of deflection formulas for FRP-RC members." J. Compos. Constr., 10(3), 183-194.

Newhook, J., Ghali, A., and Tadros, G. (2002). "Cracking and deformability of concrete flexural sections with fiber reinforced polymer." J. Struct. Eng., 128(9), 1195-1201.

Oh, H., Moon, D. Y., and Zi, G. (2009). "Flexural characteristics of concrete beams reinforced with a new type of GFRP bar." Polym. Polym. Compos., 17(4), 253-264.

Pecce, M., Manfredi, G., and Cosenza, E. (2000). "Experimental response and code models of GFRP RC beams in bending." J. Compos. Constr., 4(4), 182-190.

Rafi, M. M., and Nadjai, A. (2009). "Evaluation of ACI 440 deflection model for fiber-reinforced polymer reinforced concrete beams and suggested modification." ACI Struct. J., 106(6), 762-771.

Rafi, M. M., Nadjai, A., Ali, F., and Talamona, D. (2008). "Aspects of behavior of CFRP reinforced concrete beams in bending." Constr. Build. Mater., 22, 277-285.

Rasheed, H. A., Nayal, R., and Melhem, H. (2004). "Response prediction of concrete beams reinforced with FRP bars." Compos. Struct., 65(2), 193-204.

Razaqpur, A. G., Svecova, D., and Cheung, M. S. (2000). "Rational method for calculating deflection of fiber reinforced polymer reinforced beams." ACI Struct. J., 97(1), 175-184.

Toutanji, H., and Deng, Y. (2003). "Deflection and crack-width prediction of concrete beams reinforced with glass FRP rods." Constr. Build. Mater., 17, 69-74.

Yost, J. R., Gross, S. P., and Dinehart, D. W. (2003). "Effective moment of inertia for glass fiber-reinforced polymer-reinforced concrete beams." ACI Struct. J., 100(6), 732-739. 